\title{
Spectrum analysis of national greenhouse gas emission: a case study of Germany
}

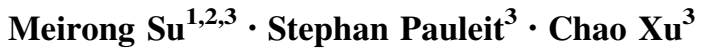 \\ ${ }^{1}$ School of Chemistry and Environmental Engineering, Dongguan University of Technology, Dongguan 523808, Guangdong Province, China \\ ${ }^{2}$ State Key Joint Laboratory of Environment Simulation and Pollution Control, School of Environment, Beijing Normal University, \\ Beijing 100875, China \\ ${ }^{3}$ Strategic Landscape Planning and Management, Technical University of Munich, 85354 Freising, Germany
}

Received: 4 May 2016/Revised: 17 June 2016/Accepted: 18 June 2016/Published online: 8 July 2016

(c) Joint Center on Global Change and Earth System Science of the University of Maryland and Beijing Normal University and Springer-Verlag Berlin Heidelberg 2016

\begin{abstract}
It is essential to abstract the key information from accounting results of greenhouse gas (GHG) emissions because it can provide a highly generalized and clear picture of GHG emissions, which is especially helpful for the public and policy makers. To clearly display the composition of GHG emissions, the concept of spectrum analysis is introduced and defined in this paper. Next, a multilayer analysis framework for national GHG emissions was proposed, which is represented by a pyramid of three layers: total emissions (first layer), emissions decomposed by gas type or sector (second layer), and emissions decomposed by both gas type and sector (third layer). Based on the analysis results from the first to third layers, the main compositional information of national GHG emissions was gradually summarized and analyzed until a spectrum of GHG emissions was acquired. The spectrum of GHG emissions displays the compositional structure of national GHG emissions in the different layers, which is helpful in identifying priorities for emissions reduction. A case study of Germany's GHG emissions during 1990-2012 was conducted, which indicated that $\mathrm{CO}_{2}$ and the energy sector were the biggest contributors to the total GHG emissions. Some suggestions for reducing GHG emissions are offered based on the obtained results. And the potential development of spectrum analysis for GHG emissions is also expected from aspects of both research and technology.
\end{abstract}

Meirong Su

sumr@dgut.edu.cn
Keywords Greenhouse gas emissions · Spectrum analysis - Sectoral decomposition - Multilayer analysis framework - Germany

\section{Introduction}

Global climate change affects all our lives and it has greatly influenced, and will continue to influence global socioeconomic development. Stern has estimated that the overall costs and risks of climate change are equivalent to losing at least $5 \%$ of annual global GDP, which could rise to more than $20 \%$ of annual global GDP where a wider range of risks and impacts included (Stern 2006; Su et al. 2012). Considerable effort has been made globally to adapt to and mitigate the effects of climate change. For example, since its foundation in 1988, the Intergovernmental Panel on Climate Change has issued the United Nations Framework Convention on Climate Change (UNFCCC) in 1992, published five assessment reports on climate change, as well as other special reports, methodology reports, and technical papers.

A series of studies has been published on the accounting of GHG emissions on global (Houghton et al. 1995; Matsuo et al. 2012), national (Chen and Zhang 2010; Choi and Ang 2001), regional (Garg et al. 2001; Salt and Moran 1997; Zhang et al. 2014), urban (Glaeser and Kahn 2010; Hao et al. 2015; Zhao et al. 2014), and sectoral scales (Flessa et al. 2002; de Jong et al. 2010; Liu et al. 2015; Lu et al. 2013; Olonscheck et al. 2011). The accounting methods used can be largely grouped into two types: inventory methods and input-output analysis methods. Based on the former method, Choi and Ang (2001) 
estimated the energy-related carbon emissions in Korea, Glaeser and Kahn (2010) estimated GHG emissions in 66 American cities, Dhakal (2004) estimated GHG emissions in four Asian megacities, Perch-Nielsen et al. (2010) evaluated the GHG emissions of tourism in Switzerland, and Streets et al. (2001) estimated the $\mathrm{CO}_{2}$ emissions caused by fossil fuel combustion in China in 2000. Based on the latter method, Houghton et al. (1995) have estimated the global $\mathrm{CO}_{2}$ emissions caused by fossil fuel consumption and cement production in the 1980s, Chen and Chen (2011) applied a multiregion input-output model to analyze $\mathrm{CO}_{2}$ emissions due to fossil fuel combustion on a supranational scale, Chen and Zhang (2010) estimated the GHG emissions by the Chinese economy in 2007, Liu et al. (2011) evaluated China's carbon emissions from urban and rural households during 1992-2007, Fan et al. (2012) evaluated the carbon emissions from urban households, and Shao et al. (2014) estimated the carbon emissions of urban buildings. In addition, there have also been other accounting studies based on some specific models. For instance, Houghton and Hackler (1999) estimated the carbon emissions caused by land-use change based on a bookkeeping model, You et al. (2011) analyzed the carbon emissions of urban buildings based on an integrated life cycle model, and Christen et al. (2010) simulated carbon emissions based on approaches involving urban metabolism and remote sensing on the neighborhood scale.

Herein, we do not wish to judge which accounting method is better. Indeed, it is arbitrary and unwise to declare which method might be better because each has its own advantages and disadvantages and different methods could be adopted in different cases based on the research goals and data acquisition situation (Salt and Moran 1997). On the contrary, we want to discuss what information can be obtained from the accounting results and how best to use it in management.

There are two potential avenues: One is to conduct further analysis (e.g., relationship analysis and factor decomposition) by combining the results with other related data (e.g., energy structure, energy intensity, population, and economic growth) and the other is to summarize and abstract the most important information directly from the accounting results. Using the former method, Matsuo et al. (2012) analyzed the effects of constraints on $\mathrm{CO}_{2}$ emissions on the world's energy supply/demand structure and energy supply costs based on the MARKAL (MARKet ALlocation) model. Hossain (2012) examined the dynamic causal relationships between $\mathrm{CO}_{2}$ emissions, energy consumption, economic growth, foreign trade, and urbanization in Japan. Chang and Lin (1999) identified the key factors affecting energy-induced $\mathrm{CO}_{2}$ emission changes from 34 industries in Taiwan based on gray relational analysis. Ren et al. (2014) applied the Log Mean Divisia
Index method to explore the impacts of energy structure, energy intensity, industry structure, and economic output on total $\mathrm{CO}_{2}$ emissions from China's manufacturing industry. However, scientific discussion about the latter method oriented to efficient management appears to have been somewhat neglected although some accounting results have been displayed by many organizations and institutes such as IEA (2014), IPCC (2014), EEA (2014), WRI (2014), CDIAC (2015), and EDGAR (2015). It is clear that the analysis of the former method can be significant for identifying the key factors based on models and for guiding GHG emissions reduction. However, the direct abstraction of the accounting results is also essential, because it can reveal a clear picture of GHG emissions for the public and policy makers.

In this paper, the concept of spectrum analysis is proposed, under whose guidance the important information is abstracted layer by layer from the accounting results of GHG emissions. The highly generalized spectrum of GHG emissions is finally generated, which will facilitate the decision-making process. Because of the abundance of data, this paper focuses on national-scale GHG emissions.

The remainder of this paper is structured as follows: Sect. 2 presents the concept of spectrum analysis and the multilayer analysis framework for national GHG emissions and also introduces the calculation methods. The following two sections present the results and further discussion, respectively, and our conclusions are offered in Sect. 5.

\section{Methodology}

\subsection{Concept of spectrum analysis for GHG emissions}

Spectrum analysis is a concept widely applied in such disciplines as physics, chemistry, and medicine. With various connotations and emphases in different disciplines, the common function for spectrum analysis is that it can abstract the embodied information and illustrate the concrete composition of specific materials (or signals). In order to clearly display the components of GHG emissions in a concise and generalized way, the concept of spectrum analysis is introduced in this paper, which is specified as "the information embodied in data of GHG emissions is abstracted layer by layer to finally acquire a highly integrated structure chart of GHG emissions where the contributions of different gases and sectors are generalized clear." The basic steps of spectrum analysis for GHG emissions are shown in Fig. 1, in which GHG emissions is first decomposed by the sector and then by the gas type. The reverse analysis order is also acceptable. It should be pointed out that, besides the static spectrum analysis in a 
Fig. 1 Sketch of spectrum analysis for GHG emissions (the composition of GHG emissions becomes clearer and clearer based on the step-by-step spectrum analysis, which is represented by the lighter and lighter color of the columns.

The sectors (or gases) are ranked according to their contributions to the total GHG emissions, i.e., the sector (or gas) at the top of the column has the biggest contribution to the total emissions while that at the bottom has the smallest contribution)

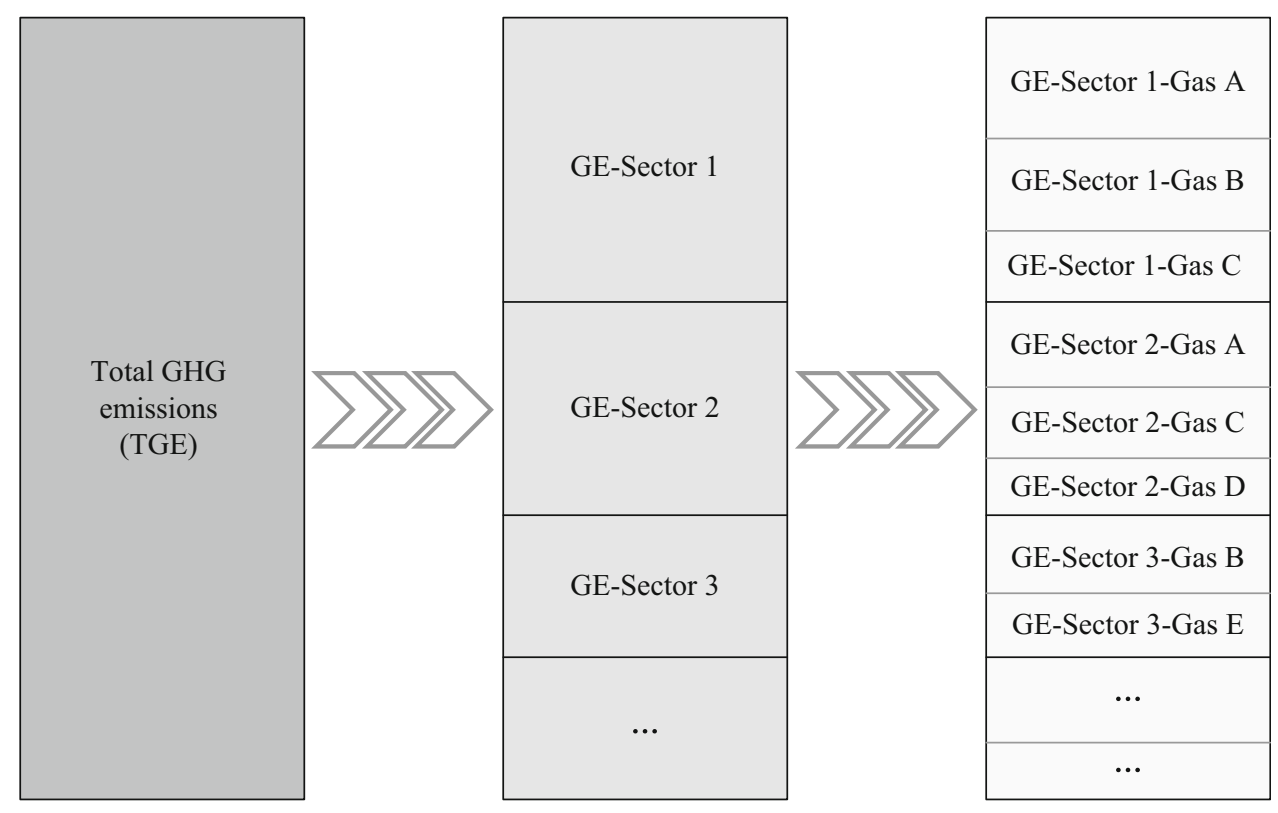

specific time point, the dynamic spectrum analysis can also be conducted by investigating the changes in GHG emissions in a period.

\subsection{Multilayer analysis framework for national GHG emissions}

For national GHG emissions, there are usually two main problems: establishing what gases are emitted and from which sectors. When obtaining national data of GHG emissions over several years, another important problem emerges, i.e., the temporal trend of change. Emissions can be described using the function in Eq. (1):

$E=f(G, S, T)$

where $E$ is the national GHG emissions, $G$ is the type of gas, $S$ means the emission sector, and $T$ represents the time interval.

Based on this function for national GHG emissions and the idea of spectrum analysis, a multilayer analysis framework can be established (Fig. 2), from which the GHG emissions can be decomposed from different aspects and the corresponding findings from the different layers used in emission management. The analysis framework for national GHG emission is represented by a pyramid that includes three layers: total emissions (first layer), emissions analyzed by gas type or sector (second layer), and emissions analyzed by both gas type and sector (third layer).

First, the change trend of the total emissions of all kinds of GHGs from all sectors is summarized to provide an overall understanding of the national GHG emissions. The function can be represented as $E_{i}=f\left(G, S, T_{i}\right)$, where $E_{i}$ is the emissions of all GHGs from all sectors in the $i$ th time interval (usually in the units of years) and $T_{i}$ represents the $i$ th time interval. The results of this layer are helpful in comprehensively investigating the change trend of national GHG emissions, checking the effects of certain policies and measures such as energy saving and emission reductions, as well as for making comparisons with other countries.

Second, the GHG emissions are decomposed from one aspect, i.e., gas type or sector. The function on this layer is represented as $E_{p i}=f\left(G_{p}, S, T_{i}\right)$ or $E_{k i}=f\left(G, S_{k}, T_{i}\right)$, where $E_{p i}$ is the emission of the $p$ th gas from all sectors in the $i$ th time interval, $E_{k i}$ is the emission of all GHGs from the $k$ th sector in the $i$ th time interval, $G_{p}$ means the $p$ th gas, and $S_{k}$ represents the $k$ th sector. The results of this layer can be used for identifying the key sectors or gases, which can help in realizing the contributions of different gases and sectors to the total GHG emissions, and for providing macroscopic guidance with regard to emission reductions.

Third, the GHG emissions are further decomposed from both aspects of gas type and sector. The function can be represented as $E_{p k i}=f\left(G_{p}, S_{k}, T_{i}\right)$, where $E_{p k i}$ is the emission of the $p$ th gas from the $k$ th sector in the $i$ th time interval. The results of this layer provide detailed information on the contributions of each gas and sector to the total GHG emissions, and provide practical guidance for the development of regulations.

\subsection{Calculation methods}

Although the multilayer analysis framework for GHG emissions displays a top-down process, the actual data collection and calculation is a bottom-up process. Based on the data of $E_{p k i}$, further calculation and analysis is possible. 
Fig. 2 Multilayer analysis framework for national GHG emissions based on spectrum analysis

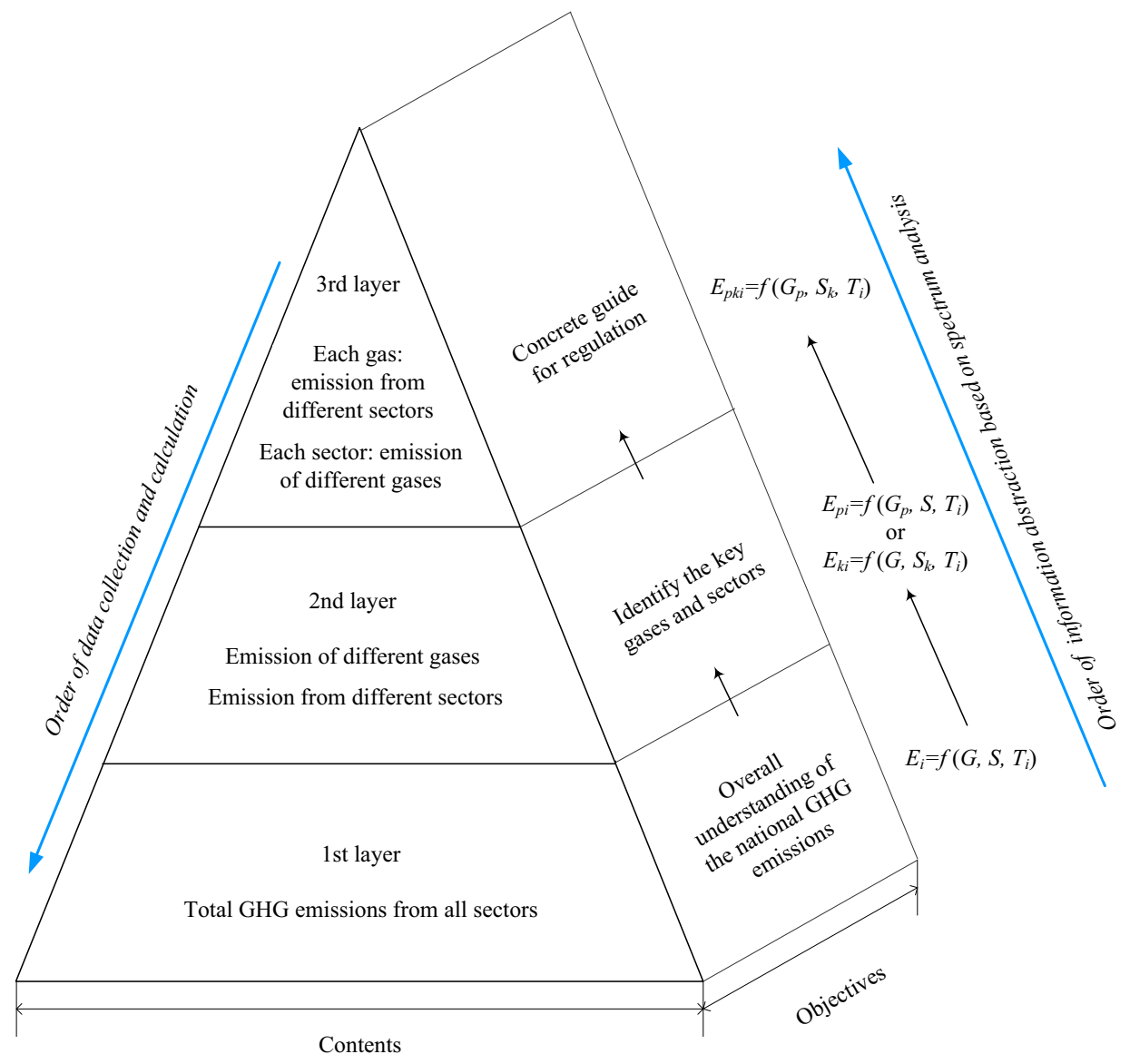

First, the amounts of GHG emissions on the layer of gas type or sector can be calculated by Eqs. (2) or (3), respectively:

$E_{p i}=\sum_{k=1}^{\mathrm{n}} E_{p k i}$

$E_{k i}=\sum_{p=1}^{\mathrm{m}} E_{p k i}$

where $n$ is the total amount of sectors and $m$ is the amount of gas types. Sectors are usually divided into six categories (i.e., $n=6$ ), which include energy, industrial processes (IP), solvents and other product use (SOPU), agriculture, land use, land-use change and forestry (LULUCF), and waste. Generally, gases include direct GHGs, i.e., those that contribute directly to the greenhouse effect, such as $\mathrm{CO}_{2}$, $\mathrm{CH}_{4}, \mathrm{~N}_{2} \mathrm{O}$, hydrofluorocarbons (HFCs), perfluorocarbons (PFCs), and $\mathrm{SF}_{6}$, and indirect GHGs, i.e., those that do not impact directly on the greenhouse effect in their own forms, but quickly form substances that do, once they are released into the atmosphere. Usual examples include $\mathrm{NO}_{\mathrm{x}}, \mathrm{CO}$, non-methane volatile organic compounds, and $\mathrm{SO}_{2}$.

From the perspective of the greenhouse effect, different GHGs should be first unified in a common unit to permit their summing up and comparison. The unit transformation is finished based on Eq. (4):

$E_{p}=G W P_{p} \times E_{p-o}$

where $E_{p}$ is the amount of the $p$ th gas in the common unit, $E_{p-o}$ is the amount of the $p$ th gas in the original emission unit (e.g., g, kg, t, and other weight units), and $G W P_{p}$ is the global warming potential of the $p$ th gas. The global warming potential is defined as the cumulative radiative forcing between the present and specific time horizon (here 100 years is chosen; see IPCC 2016) caused by a unit mass of gas emitted now, expressed relative to that for some reference gas (IPCC 1996). Usually, $\mathrm{CO}_{2}$ is used for the reference gas for which the GWP is defined as 1; thus, other gases are expressed in the weight units of $\mathrm{CO}_{2}$ equivalent. There is a lack of acknowledged $G W P$ for the indirect GHGs due to the difficulty of quantifying the relationships among the indirect GHGs and the actual greenhouse effect, which induces only the direct GHGs are considered herein.

\subsection{Spectrum of national GHG emissions}

Based on the calculation results from the first to third layers, the main information of national GHG emissions 
(e.g., the amount and proportion of GHG emissions to the total GHG emissions at the higher layer) can be summarized and decomposed step by step. Finally, the composition table of national GHG emissions for the different layers can be acquired. We name it a spectrum of $\mathrm{GHG}$ emissions because the step-by-step process of decomposition is similar to that used in analytical chemistry and the composition table of GHG emissions layer by layer does look like a spectrum. The spectrum displays the results for the three layers, where the amount and proportion of GHG emissions by different gases and sectors are generalized, and it shows a clear structure of GHG emissions for the different layers.

\subsection{Data sources}

A national emission inventory is required to complete the national emissions analysis. The national inventory report (NIR) and common reporting format (CRF) submitted under the UNFCCC and the Kyoto Protocol provide detailed data of all GHG emissions and removals (UNFCCC 2014). In this study, we focus on Germany, which in 1987, became the fourth largest contributor in the world of $\mathrm{CO}_{2}$ emissions (Molt et al. 1996), and it is one of the largest carbon emitters in the European Union (Schumacher and Sands 2006). The NIR 1990-2012 and CRF submitted by the Federal Environment Agency of Germany in April 2014 were obtained via the UNFCCC website.

\section{Results}

\subsection{Total GHG emissions in Germany}

The results from the first level of the multilayer analysis framework are shown in Fig. 3, where the emissions of all GHGs from all sectors are summed up in the units of $\mathrm{CO}_{2}$ equivalent. It can be seen that the total GHG emissions in Germany gradually decrease from 1990 to 2012, while

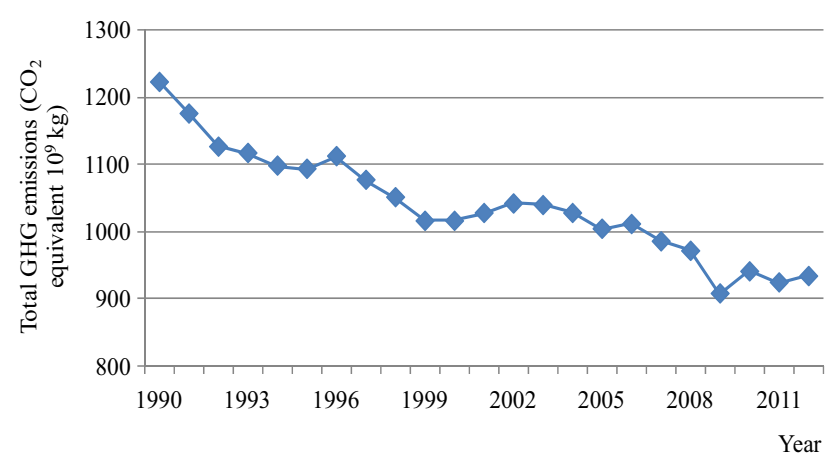

Fig. 3 Total GHG emissions in Germany during 1990-2012 there are certain fluctuations during 1995-1997, 2000-2004, and 2009-2012. In 1990, the total GHG emissions were $1224 \times 10^{9} \mathrm{CO}_{2}$ equivalent $\mathrm{kg}$, which fell to $936 \times 10^{9} \mathrm{CO}_{2}$ equivalent $\mathrm{kg}$ in 2012 , showing a rate of decline of $23.5 \%$.

\subsection{GHG emissions in Germany decomposed by gas type or sector}

The results from the second level of the multilayer analysis framework are shown in Figs. 4 and 5, where the GHG emissions are analyzed from the aspects of gas type and sector, respectively. Figure 4 reveals that $\mathrm{CO}_{2}$ accounted for 83-88\% of total GHG emissions during 1990-2012, followed by $\mathrm{CH}_{4}$ and $\mathrm{N}_{2} \mathrm{O}$, which accounted for 5-9 and 6-7 \%, respectively, of total GHG emissions. The other three gases (HFCs, PFCs, and $\mathrm{SF}_{6}$ ) in combination accounted for only about $1 \%$ of total GHG emissions.

Except for HFCs, all the other gases generally decreased during the study period. Although HFCs gradually increased during the study period (Fig. 4d) and $\mathrm{SF}_{6}$ exhibited an obvious increase during 1990-1995 (Fig. 4f), this has not changed the overall decreasing trend of total GHG emissions (Fig. 3). On the contrary, it was found that the overall trend of change in total GHG emissions was affected considerably by $\mathrm{CO}_{2}$ emissions, which is proved by the similar trends of change shown in Figs. 3 and $4 \mathrm{a}$. This is predictable because $\mathrm{CO}_{2}$ is the biggest contributor to the total GHG emissions.

Figure 5 shows that the energy sector contributed most to the total GHG emissions, accounting for $82-85 \%$ during 1990-2012. The contributions from the other sectors in decreasing order were IP (7-9\%), agriculture (7-8\%), waste (1-4\%), and SOPU (0.2-0.4\%).In terms of LULUCF, it contributed $0.8-0.9 \%$ of the total GHG emissions during 2002-2007, but it usually acts as a sink to remove GHG emissions (Fig. 5e). The biggest rate of removal of $2.7 \%$ occurred in 2001, when the amount of GHG removed reached $28 \times 10^{9} \mathrm{CO}_{2}$ equivalent $\mathrm{kg}$.

Except for LULUCF, the sectors contributing to GHG emissions show a general trend of decline during 1990-2012, although there are certain fluctuations for energy and IP (Fig. 5). Again, the biggest contributor was the energy sector, which influenced the overall change in total GHG emissions considerably, proved by the similar trends shown in Figs. 3 and 5a.

It has been established that $\mathrm{CO}_{2}$ and the energy sector were the biggest contributors to total GHG emissions in Germany during 1990-2012, which indicates that the results from the second level of the multilayer analysis framework for national GHG emissions can help identify the key gases and sectors. These findings are useful for confirming the direction and emphasis of national emission 
(a)

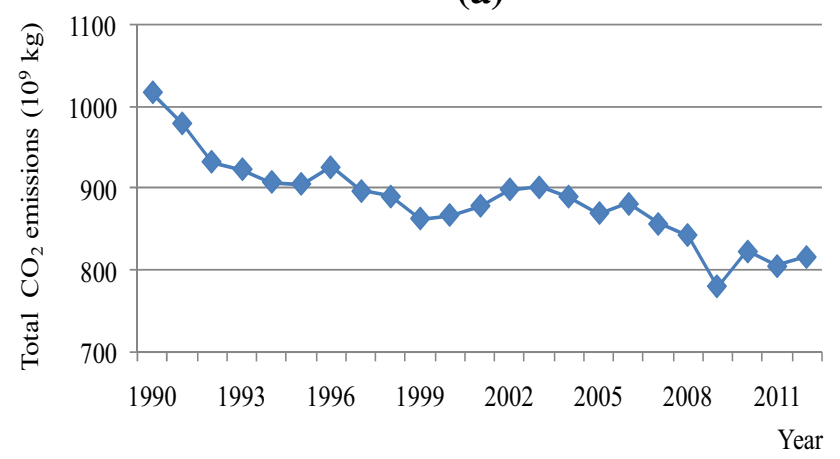

(c)

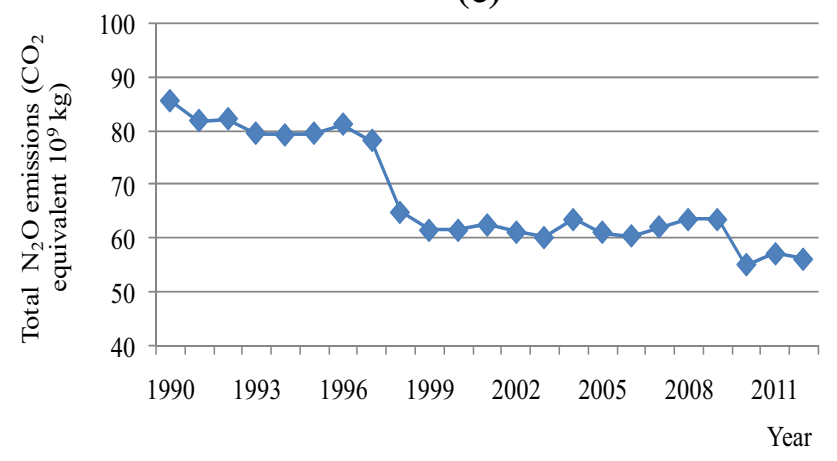

(e)

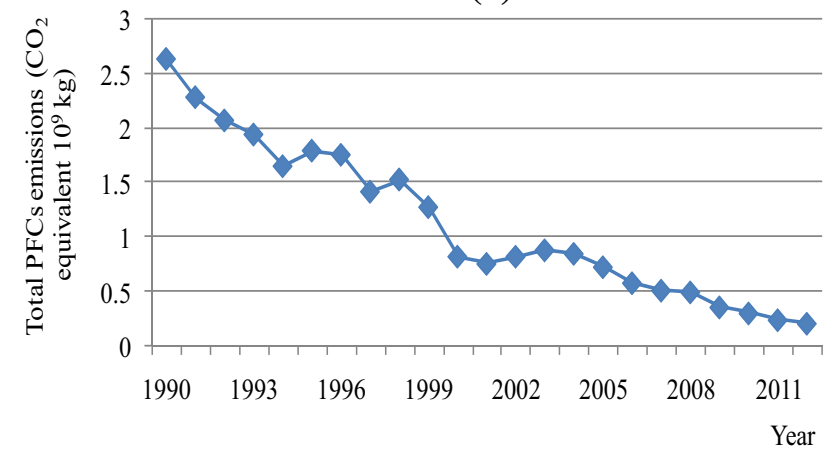

(b)

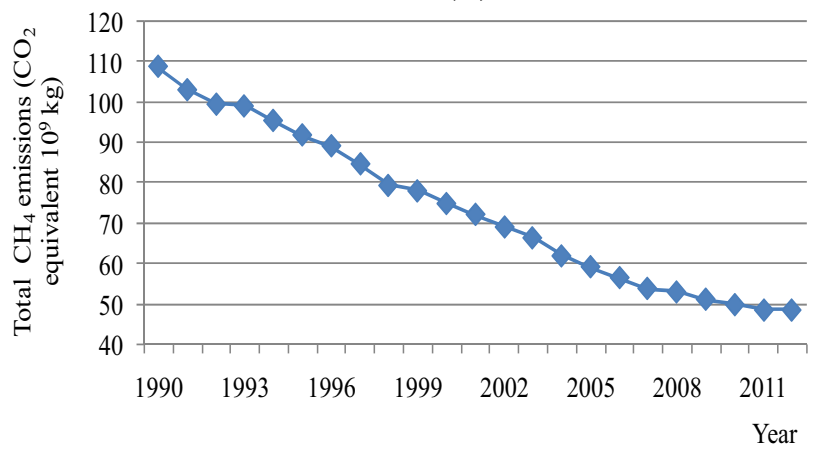

(d)

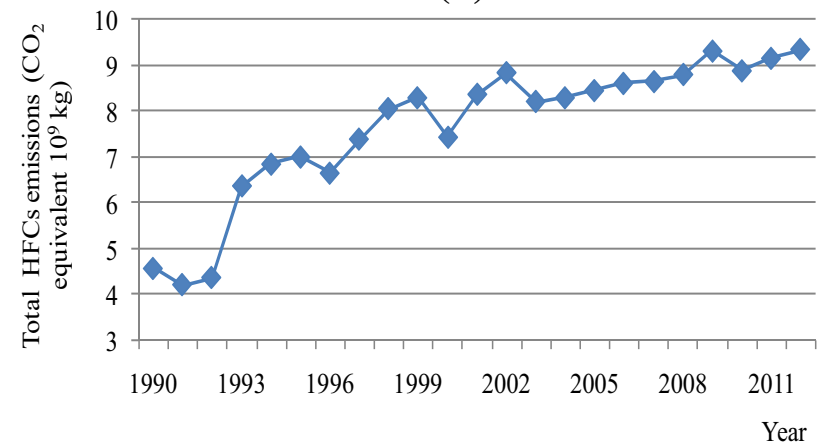

(f)

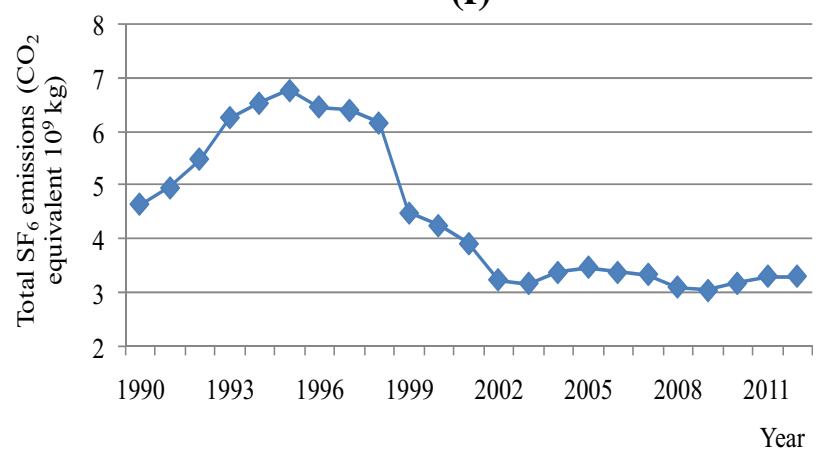

Fig. 4 Emissions of different gases in Germany during 1990-2012 (HFCs hydrofluorocarbons, PFCs perfluorocarbons)

reduction strategies. Greater attention focused on reducing $\mathrm{CO}_{2}$ emissions and GHG emissions from the energy sector will produce the greatest benefit to the reduction in GHG emissions in Germany. And considering their obvious fluctuations during the study period which implies high uncertainty and entropy, certain attention also needs to be paid to emission of HFCs and sectors of IP and LULUCF.

\subsection{GHG emissions in Germany decomposed by both gas type and sector}

The results from the third level of the multilayer analysis framework are shown in Figs. 6 and 7, where the contributions of the different sectors to the emissions of each gas and the contribution of the different gases to the emissions from each sector are analyzed, respectively. For $\mathrm{CO}_{2}$ emissions during 1990-2012, the energy sector contributed 92-97\% while IP contributed 6-7\% (Fig. 6a). During 1990-2001, LULUCF removed about 2-3\% of the $\mathrm{CO}_{2}$ (Fig. 6a). Agriculture, waste, and the energy sector contributed $31-53,22-41$, and $21-30 \%$ of $\mathrm{CH}_{4}$ emissions, respectively, during the study period (Fig. 6b). With respect to $\mathrm{N}_{2} \mathrm{O}$ emissions, agriculture and IP contributed 53-78 and 6-33\%, respectively, during 1990-2012 (Fig. 6c). The other three gases (HFCs, PFCs, and $\mathrm{SF}_{6}$ ) were emitted only by IP (Fig. 6d-f). From 1995 to 2012, when PFCs and $\mathrm{SF}_{6}$ showed a decreasing trend, HFCs showed an increase. 


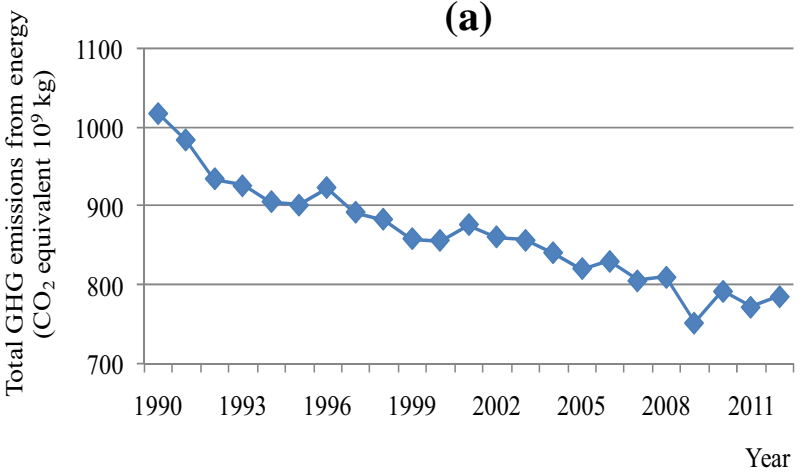

(c)

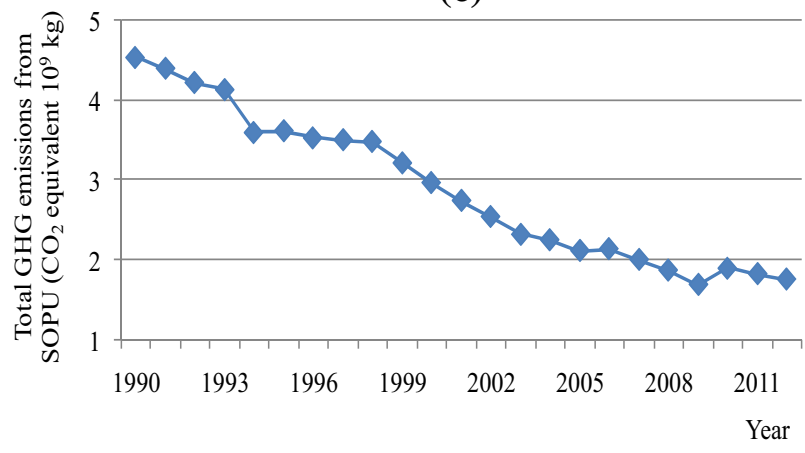

(e)

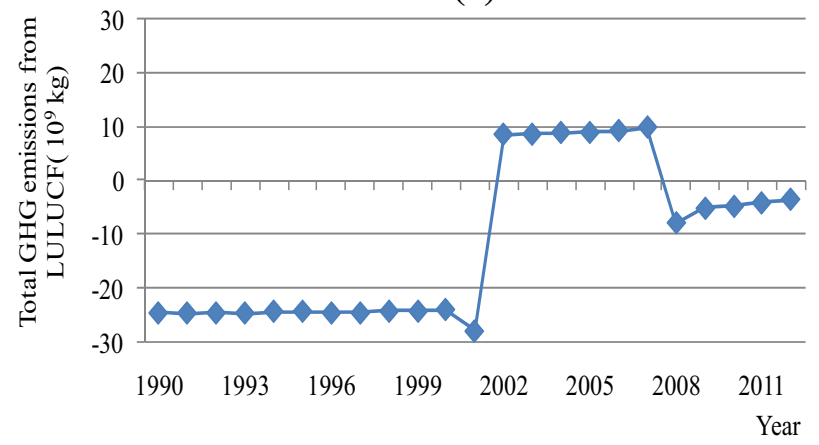

(b)

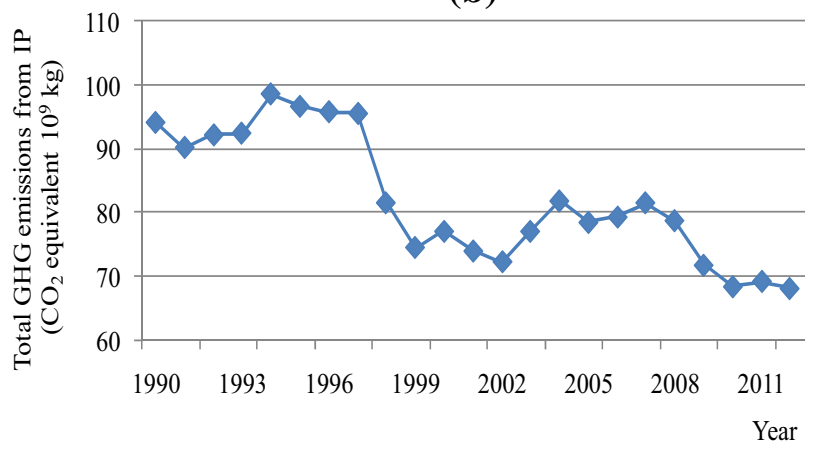

(d)

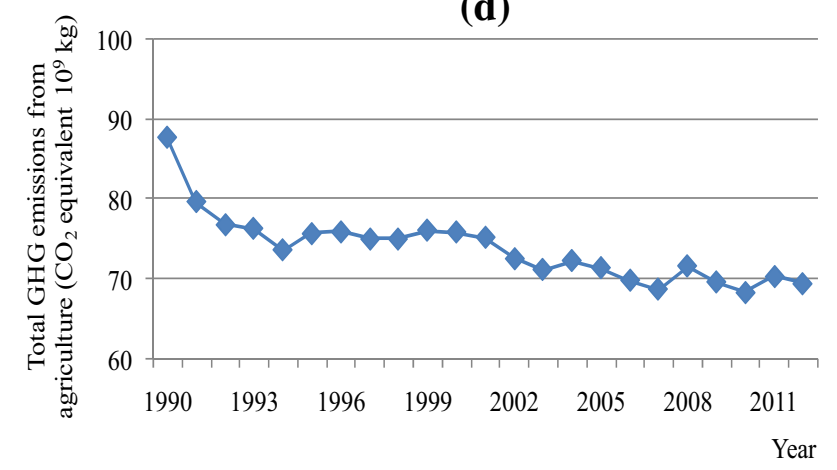

(f)

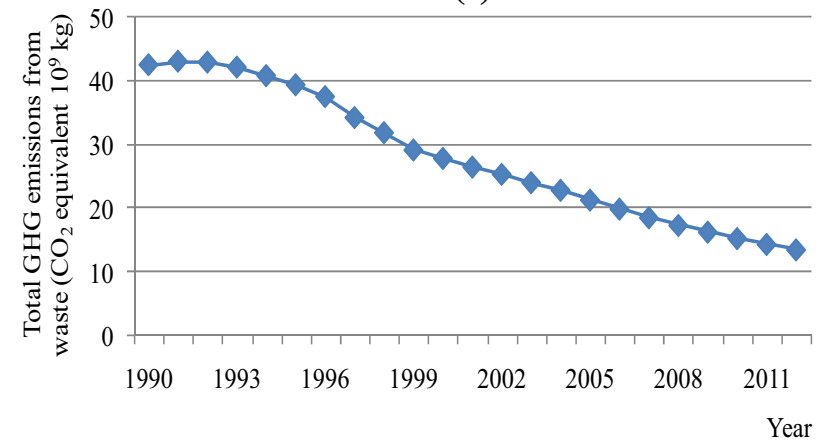

Fig. 5 GHG emissions from different sectors in Germany during 1990-2012 (IP industrial processes, SOPU solvents and other product use, LULUCF land use, land-use change and forestry)

Figure $7 \mathrm{~b}$ indicates that IP emitted all kinds of GHGs during the study period, of which $\mathrm{CO}_{2}, \mathrm{~N}_{2} \mathrm{O}$, HFCs, and $\mathrm{SF}_{6}$ accounted for 57-77, 5-28, 5-14, and 4-8\%, respectively. The energy sector produced $\mathrm{CO}_{2}, \mathrm{CH}_{4}$, and $\mathrm{N}_{2} \mathrm{O}$, of which $\mathrm{CO}_{2}$ emissions accounted for $96-98 \%$ (Fig. 7a). Although most active in removing $\mathrm{CO}_{2}$, LULUCF also emitted $\mathrm{N}_{2} \mathrm{O}$ and $\mathrm{CH}_{4}$ during 1990-2012, of which $\mathrm{N}_{2} \mathrm{O}$ was the principal emission (Fig. 7e). The other three sectors (SOPU, agriculture, and waste) emitted two gases during the study period: SOPU emitted $54-82 \%$ of $\mathrm{CO}_{2}$ and $18-46 \%$ of $\mathrm{N}_{2} \mathrm{O}$ (Fig. 7c), agriculture emitted 58-63\% of $\mathrm{N}_{2} \mathrm{O}$ and 37-42 \% of $\mathrm{CH}_{4}$ (Fig. 7d), and waste emitted 80-94\% of $\mathrm{CH}_{4}$ and 6-20\% of $\mathrm{N}_{2} \mathrm{O}$ (Fig. 7f).
Based on the analysis results from the third level of the multilayer framework for national GHG emissions, a more detailed list of GHG emission composition can be acquired. It provides clearer guidance for the actual work required for energy saving and emissions reduction; i.e., it confirms the priority of different regulations. For example, improving energy use efficiency in the energy sector is likely to produce more obvious effects on $\mathrm{CO}_{2}$ emissions reduction in Germany than developing new techniques in the IP sector, although both measures will undoubtedly contribute to emissions reduction. In terms of the energy sector, identifying the processes that produce $\mathrm{CO}_{2}$ and developing related low-carbon techniques will contribute more to GHG 
Fig. 6 Contribution of different sectors to emissions of each gas in Germany during 1990-2012 (HFCs hydrofluorocarbons, PFCs perfluorocarbons, $I P$ industrial processes, $S O P U$ solvents and other product use, $L U L U C F$ land use, land-use change and forestry) (a)

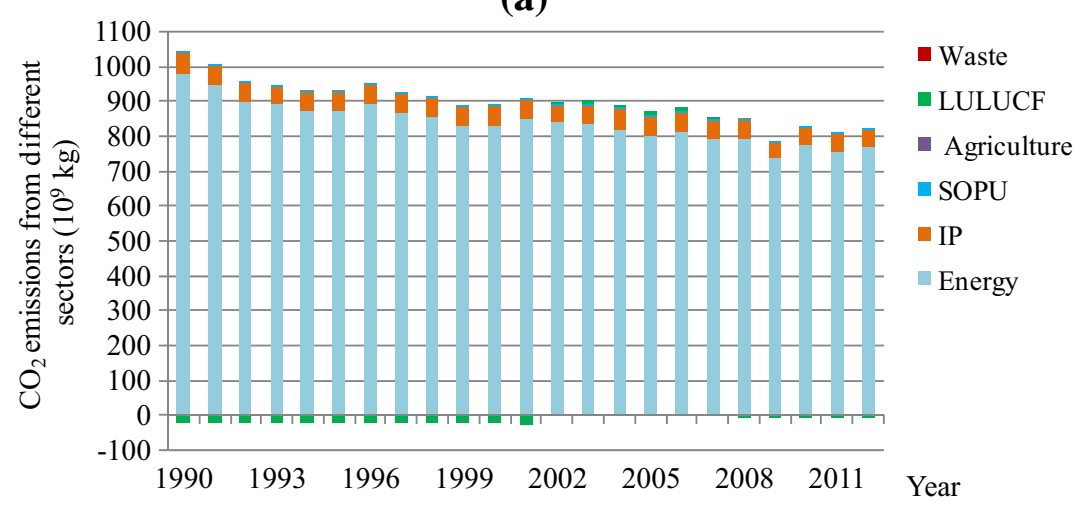

(b)

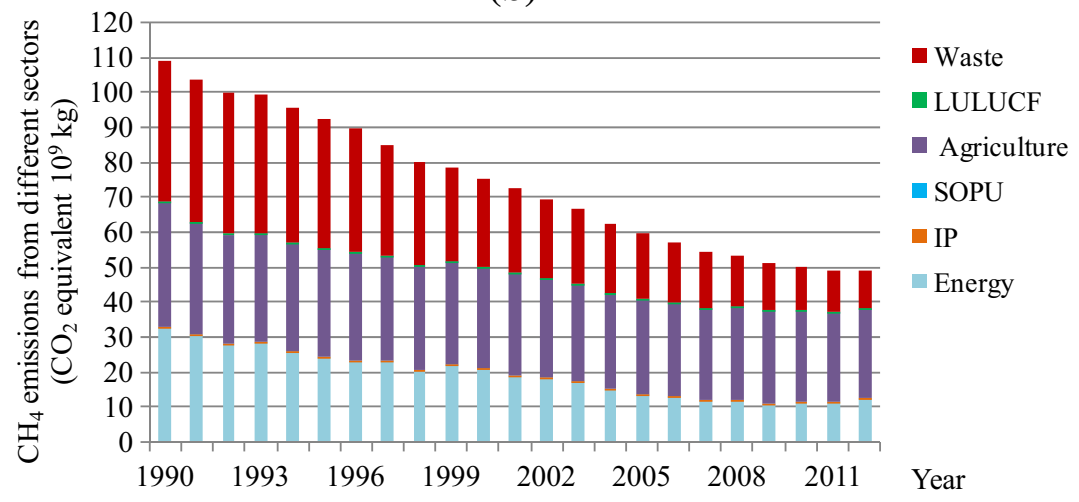

(c)

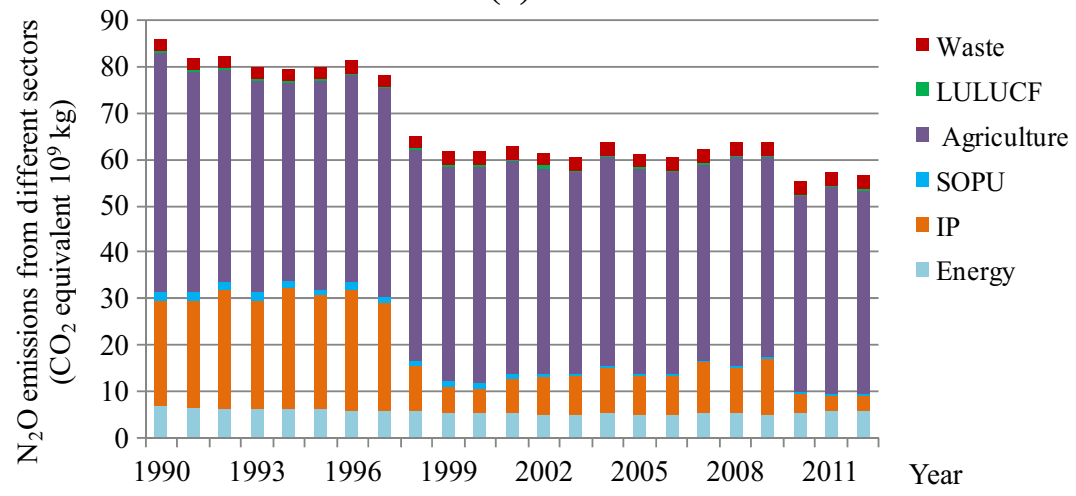

emissions reduction than focusing attention on $\mathrm{N}_{2} \mathrm{O}$. Comparatively, for sectors of IP and LULUCF, further investigation of the reason of GHG emission fluctuations will be more favorable for effective management than rashly establishing specific measures on reduction of $\mathrm{CO}_{2}$ or $\mathrm{N}_{2} \mathrm{O}$.

\subsection{Spectrum of GHG emissions in Germany}

Based on the step-by-step analysis, the spectrum of national GHG emissions can be drawn. The spectrum displays the analysis results from all layers, where different gases and sectors are ranked from high to low according to their contributions to total GHG emissions.
3.4.1 Static spectrum of German GHG emissions in 2005

Herein, only the spectrum in 2005 is shown as an example (Figs. 8, 9), which can provide a very clear picture of the national GHG emissions to the public and policy makers. Based on the spectrum, the emphasis and priority for emissions reduction is confirmed, which is not only helpful for government policy making, but also as a directive for scientific research and technological developers. The government can dictate policy for reducing $\mathrm{CO}_{2}$ emissions, e.g., by establishing strict and clear standards for $\mathrm{CO}_{2}$ emissions, confirming quantitative targets for the reduction of $\mathrm{CO}_{2}$, and supporting research and development on $\mathrm{CO}_{2}$ 
Fig. 6 continued

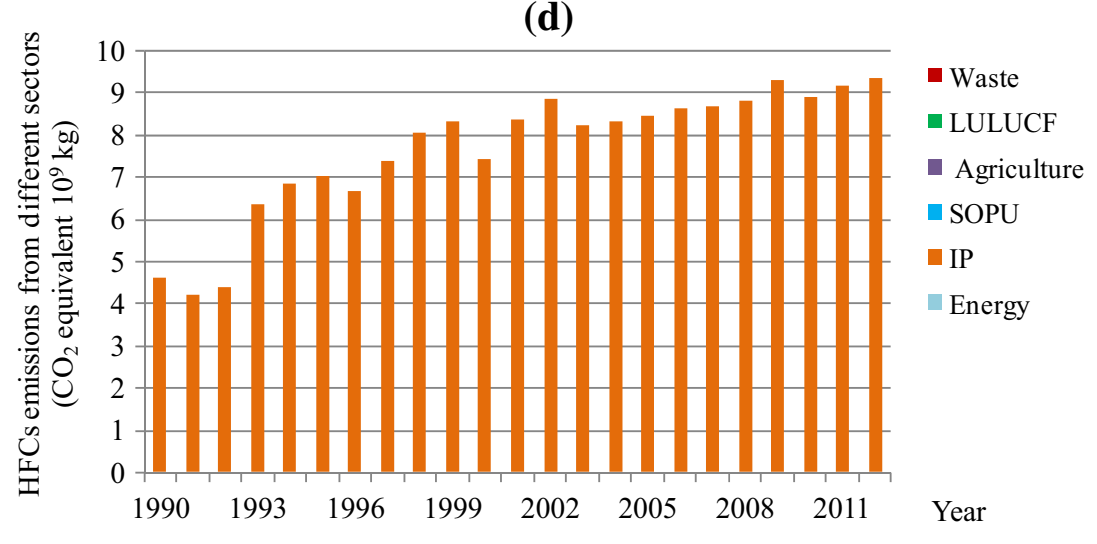

(e)

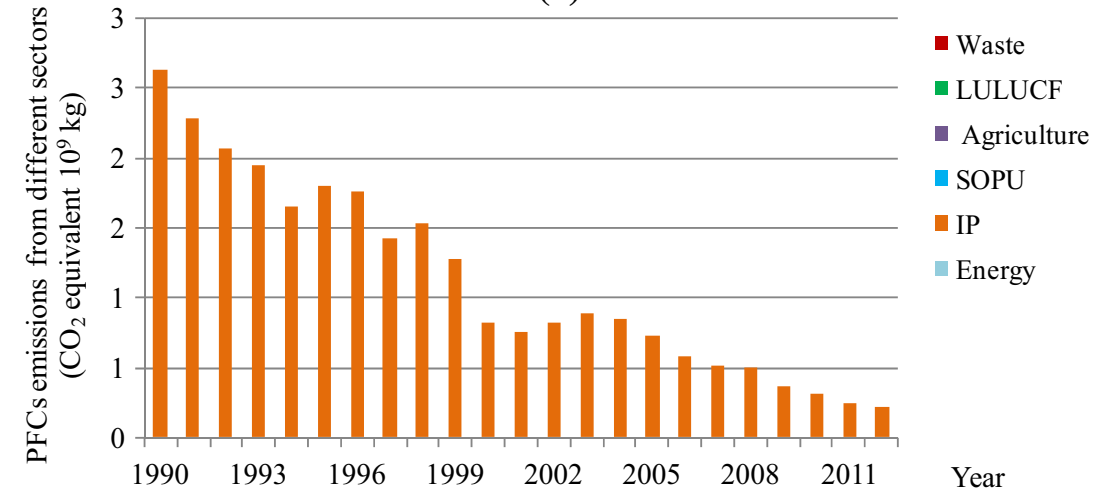

(f)

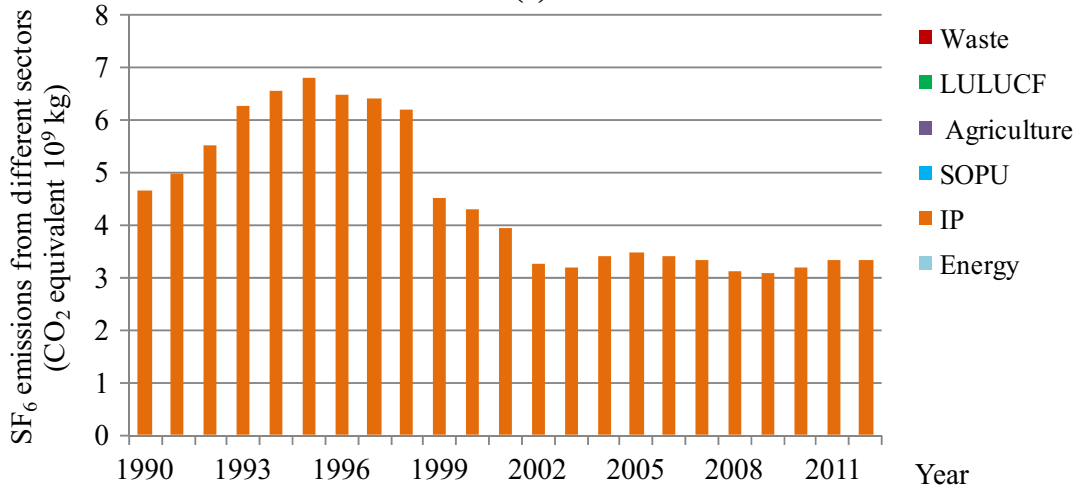

emissions reduction in the energy sector. Correspondingly, researchers and developers can devote greater effort to the subject of $\mathrm{CO}_{2}$ emissions reduction in the energy sector.

\subsubsection{Dynamic spectrum of German GHG emissions}

When comparing spectra from different years (herein choosing that in 1990, 1995, 2000, 2005, and 2010 as examples), temporal changes in the compositional structure of GHG emissions will be easily identifiable (Figs. 10, 11), which will help check the efficacy of measures implemented to reduce emissions and thus provide guidance for further regulation in the future.
It is indicated that the proportion of $\mathrm{CO}_{2}$ emissions to total GHG emissions gradually increased from 83.1 to $87.5 \%$ during the study period, although the total amount of $\mathrm{CO}_{2}$ emissions gradually decreased during the study period (Fig. 10a). Following big contributors to total GHG emissions were $\mathrm{CH}_{4}$ and $\mathrm{N}_{2} \mathrm{O}$, whose emission amount and the corresponding proportion to total GHG emissions both gradually decreased during the study period. Although the total amount of $\mathrm{CO}_{2}$ emissions from energy sector gradually decreased, the contribution of the energy sector to $\mathrm{CO}_{2}$ emissions maintained at a high level, fluctuating between 92.2 and $96.3 \%$ (Fig. 10b). Furthermore, the contribution 
Fig. 7 Emissions of different gases from each sector in Germany during 1990-2012 (IP industrial processes, $S O P U$ solvents and other product use, LULUCF land use, land-use change and forestry, $H F C s$ hydrofluorocarbons, $P F C s$ perfluorocarbons) (a)

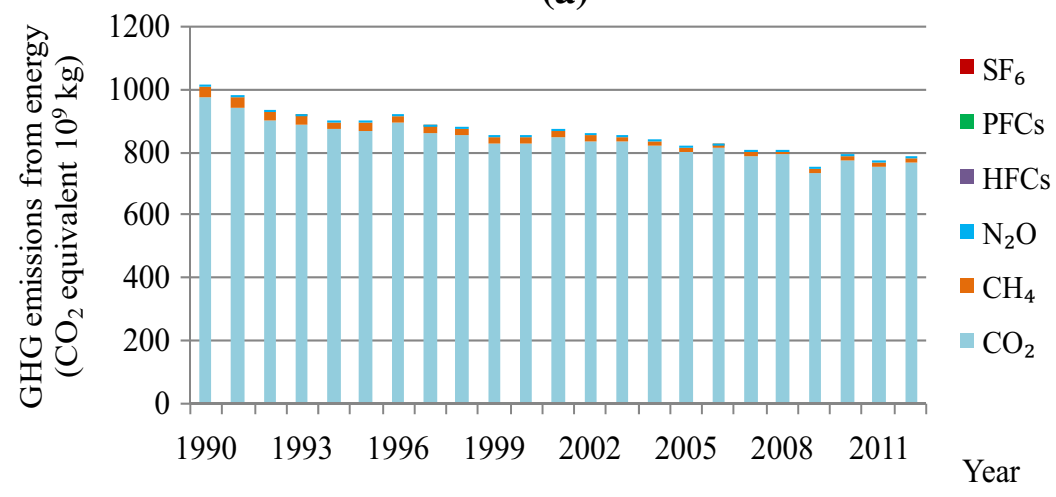

(b)

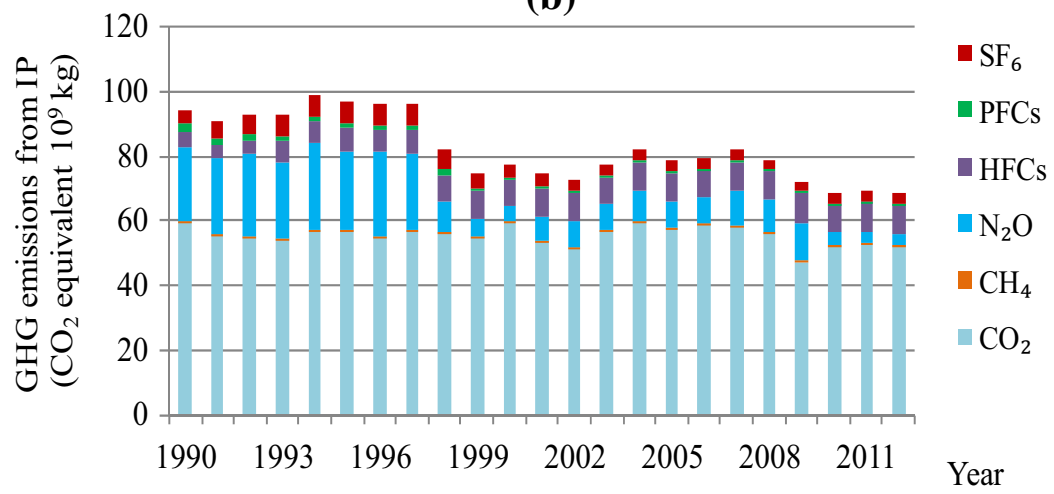

(c)

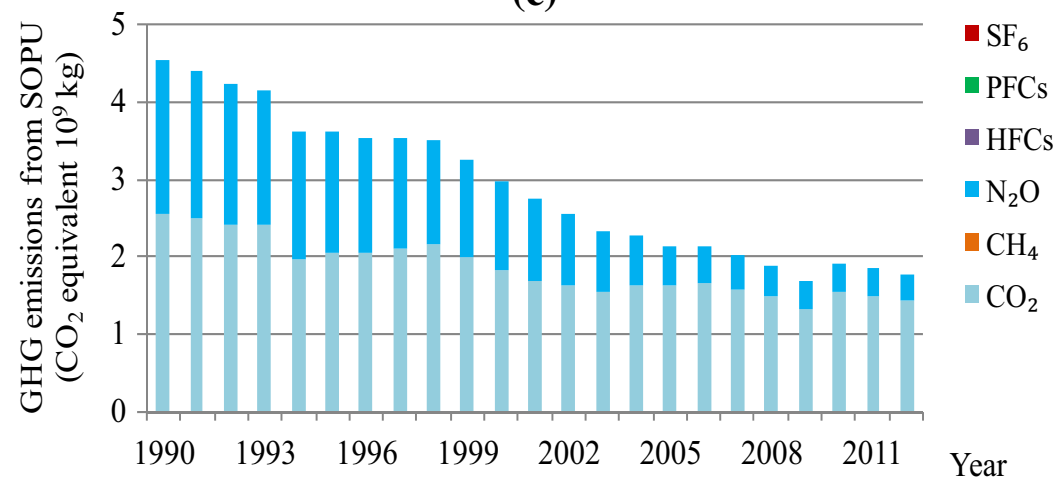

of the energy sector to GHG emissions fluctuated between 81.8 and $84.3 \%$ during the study period (Fig. 11a), and the proportion of $\mathrm{CO}_{2}$ emissions to total emissions from the energy sector has gradually increased from 96.1 to $97.9 \%$ (Fig. 11b). The gradually declined amount of GHG emissions declares the positive effects of emission reduction in the past, while other data imply that $\mathrm{CO}_{2}$ and the energy sector will remain of critical importance to the reduction in GHG emissions in the future. It still have a long way to go, on which such measures are necessary as establishing strict standards for $\mathrm{CO}_{2}$ emissions of energy utilization, improving the public's low-carbon consciousness, and quantifying the relationships between the optional measures and potential effects on GHG emissions.

\section{Discussion}

\subsection{The role of spectrum analysis}

It needs an objective understanding of the role of the spectrum analysis and the relationship between the spectrum analysis and the traditional study, e.g., the most widely used emission inventory analysis. On the one hand, 
Fig. 7 continued
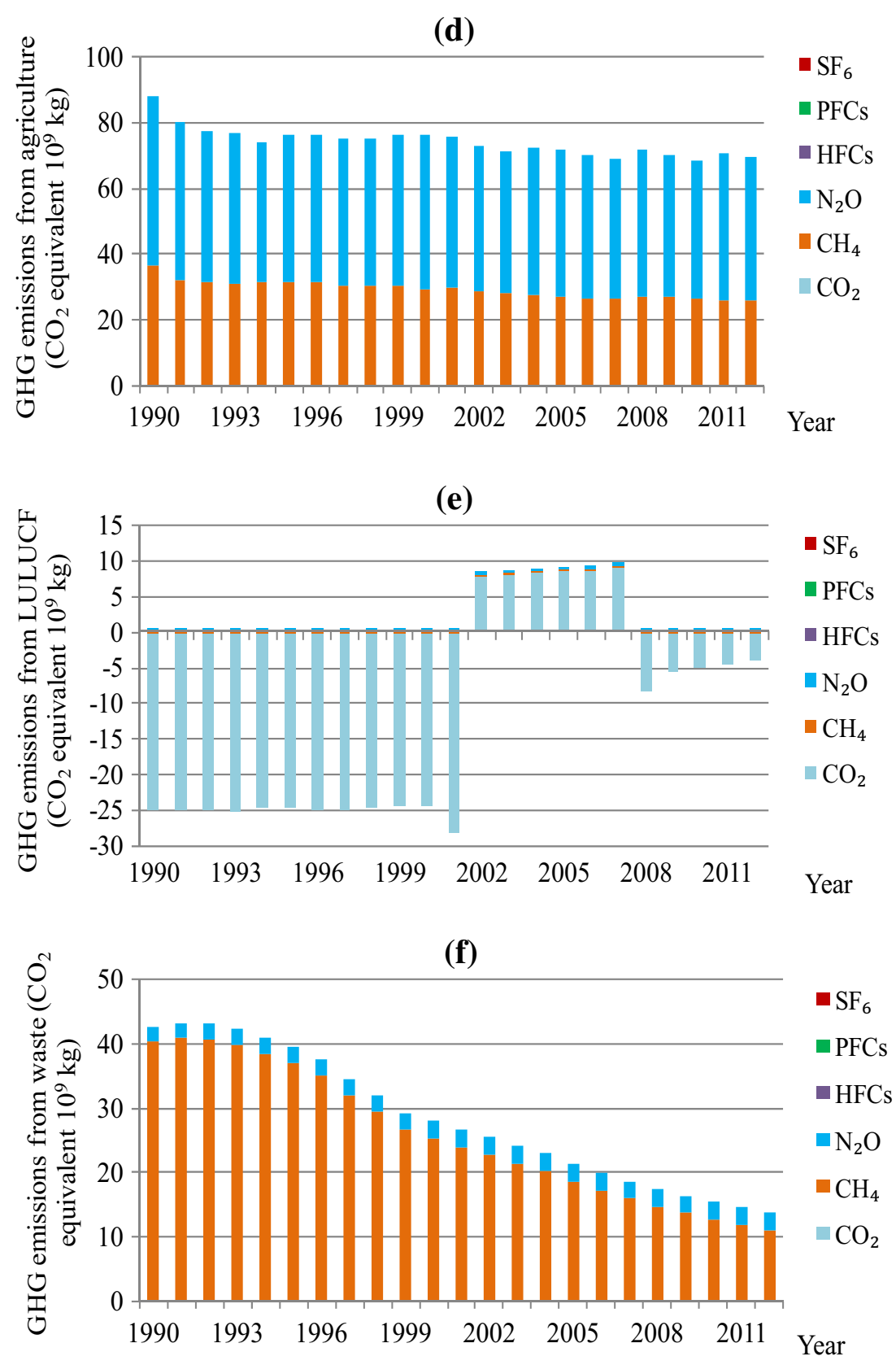

the inventory of GHG emissions provides basic data for the spectrum analysis. On the other hand, the spectrum analysis is a reprocessing of the emission inventory. They can be regarded as a unity of synthesis and analysis, in which the spectrum provides an overall contour of GHG emissions in a highly generalized and orderly pattern while the emission inventory provides the basic data and various calculation results in a more detailed pattern. The main advantage of spectrum analysis is that it can help the public and policy makers fast capture the keys of GHG emissions at a glance.
As a baseline, the spectrum analysis of GHG emissions proposed in this paper can be further developed in the future. The following two subsections are two examples.

\subsection{Real-time spectrum analysis of GHG emissions based on automatic monitoring}

The first potential development of spectrum analysis for GHG emissions depends on the progress in monitoring technology (NASA 2010; Powell 2015), which is entitled as real-time spectrum analysis. It is expected that the 
Fig. 8 Spectrum of GHG emissions in Germany 2005 divided by gas type. Unit: $10^{9}$ $\mathrm{CO}_{2}$ equivalent $\mathrm{kg}$ (HFCs hydrofluorocarbons, $P F C s$ perfluorocarbons, $I P$ industrial processes, SOPU solvents and other product use, $L U L U C F$ land use, land-use change and forestry)

$1^{\text {st }}$ layer
Q: How much are the
overall emissions of
GHGs?
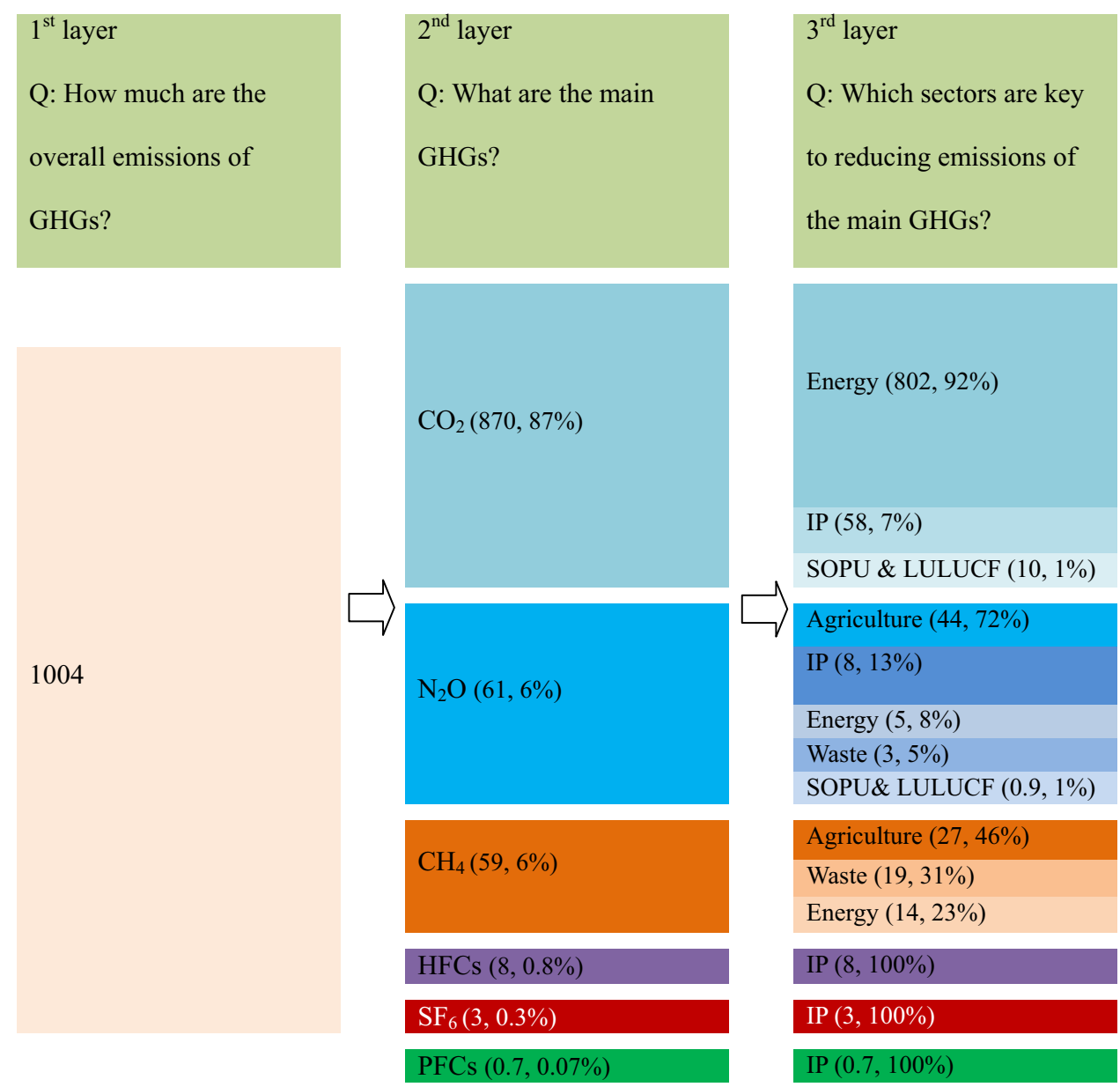

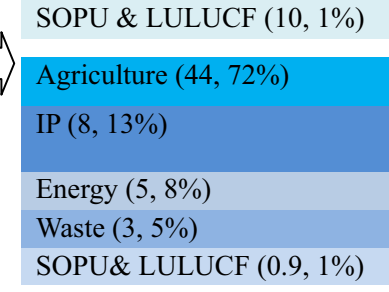

\begin{tabular}{l} 
Agriculture $(27,46 \%)$ \\
Waste $(19,31 \%)$ \\
Energy $(14,23 \%)$ \\
IP $(8,100 \%)$ \\
IP $(3,100 \%)$ \\
IP $(0.7,100 \%)$ \\
\hline
\end{tabular}

composition of GHG emissions can be obtained once the GHG passes through the monitoring equipment, similar to what we do in analytical chemistry. It is difficult to realize the real-time spectrum analysis of GHG emissions at the national or regional scale. Attempts can be first made at a smaller scale, e.g., an enterprise, and then extend to a bigger scale, e.g., a city.

\subsection{Low-entropy management based on spectrum analysis of GHG emissions}

The feature of hierarchy and order is implied in the proposed concept of spectrum analysis of GHG emissions, which is consistent with the universal goal of pursuing low entropy for various systems. This inspires us the possibility of establishing the low-entropy management framework for GHG emissions in the future.

Entropy, a basic concept describing the disorder degree of a system, has been developed and widely applied in physics, cybernetics, information science, environmental science, ecology, and enterprise management (Duan 2012; Ma 2005; Xu 2010). To avoid the terminal maximum disorder (or the dead silence) of the universe, the earth and other systems, we always make efforts to pursue low-entropy systems with higher order and attempt to obtain more and better services from various systems. Similarly, low entropy is always one of the important objectives of management, although such factors are taken into account as the economic acceptability (e.g., cost-benefit), technological feasibility, and potential interactions among different factors.

Low-entropy management for GHG emissions emphasizes both the management itself and its goal, i.e., the management should be characterized as low entropy (e.g., high order, clear information, controllability, and low uncertainty), and the goal of management is to decrease and minimize entropy of GHG emissions. It can be understood from four points: (1) highly generalized information should be abstracted to guide the emissions reduction. During the process of information generalization, negative entropy embodied in the scientific research is introduced to decrease the entropy of the management system; (2) the information embodied in data of GHG emissions should be abstracted from multiple layers 
Fig. 9 Spectrum of GHG emissions in Germany 2005 divided by sector. Unit: $10^{9} \mathrm{CO}_{2}$ equivalent $\mathrm{kg}$ (IP industrial processes, SOPU solvents and other product use, LULUCF land use, land-use change and forestry, $H F C s$

hydrofluorocarbons, $P F C s$ perfluorocarbons)

$1^{\text {st }}$ layer
Q: How much are the
overall emissions of
GHGs?

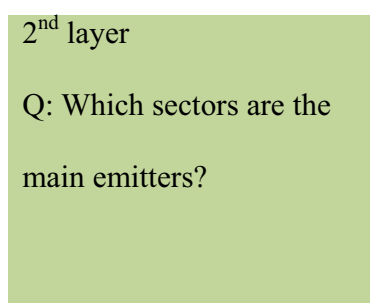

$3^{\text {rd }}$ layer

Q: What are the main

GHGs in these sectors?
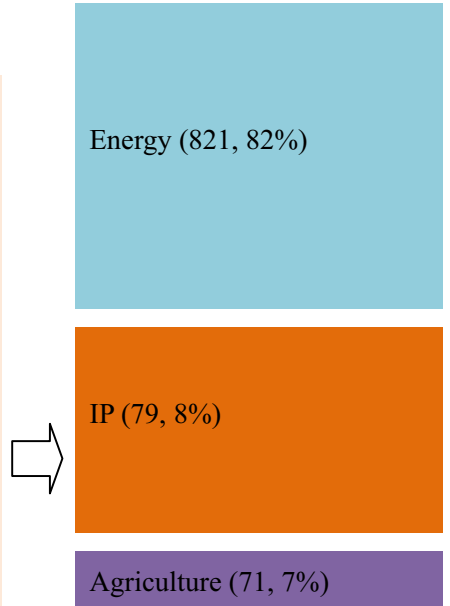

Waste $(21,2 \%)$

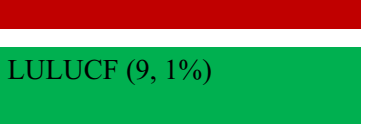

SOPU $(2,0.2 \%)$
$\mathrm{CO}_{2}(802,98 \%)$

$\mathrm{CH}_{4}(14,2 \%)$

$\mathrm{N}_{2} \mathrm{O}(5,1 \%)$

\begin{tabular}{|c|}
\hline $\mathrm{CO}_{2}(58,73 \%)$ \\
\hline $\operatorname{HFCs}(8,11 \%)$ \\
\hline $\mathrm{N}_{2} \mathrm{O}(8,10 \%)$ \\
\hline $\mathrm{SF}_{6}(3,4 \%)$ \\
\hline PFCs \& $\mathrm{CH}_{4}(1,1 \%)$ \\
\hline $\mathrm{N}_{2} \mathrm{O}(44,62 \%)$ \\
\hline $\mathrm{CH}_{4}(27,38 \%)$ \\
\hline
\end{tabular}

$\mathrm{CH}_{4}(19,87 \%)$

$\mathrm{N}_{2} \mathrm{O}(3,13 \%)$

$\mathrm{CO}_{2}(8.7,95 \%)$

$\mathrm{N}_{2} \mathrm{O}(0.4,4 \%)$

$\mathrm{CO}_{2}(1.6,77 \%)$

$\mathrm{N}_{2} \mathrm{O}(0.5,23 \%)$ (a)

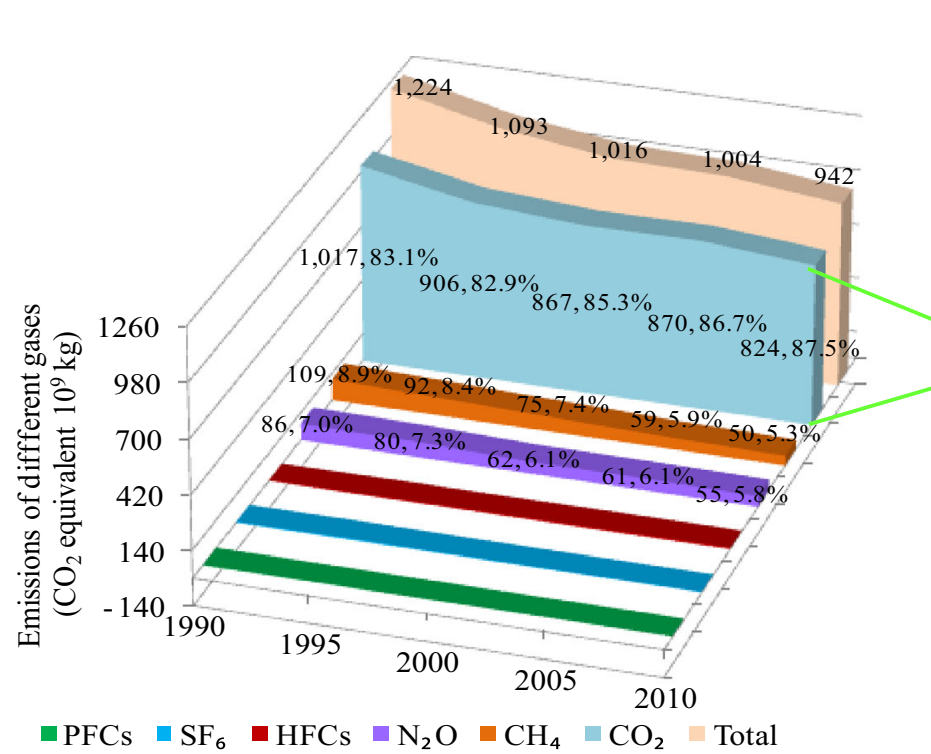

$\square \mathrm{PFCs} \quad \mathrm{SF}_{6} \quad \mathrm{HFCs} \square \mathrm{N}_{2} \mathrm{O} \quad \mathrm{CH}_{4} \square \mathrm{CO}_{2} \square$ Total (b)

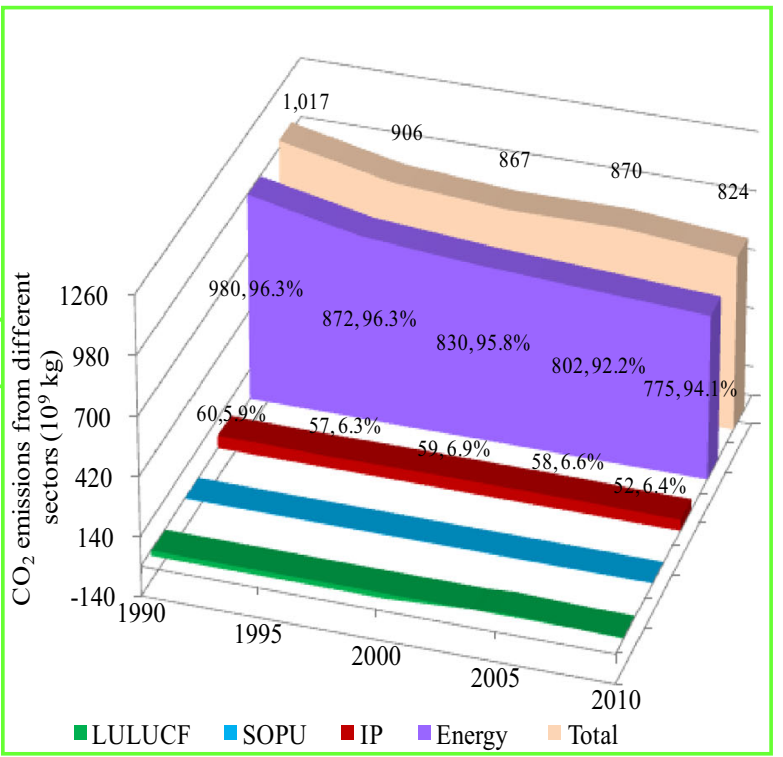

Fig. 10 Dynamic spectrum of GHG emissions in Germany divided by gas type (PFCs perfluorocarbons, HFCs hydrofluorocarbons, LULUCF land use, land-use change and forestry, SOPU solvents and other product use, $I P$ industrial processes) 
(a)

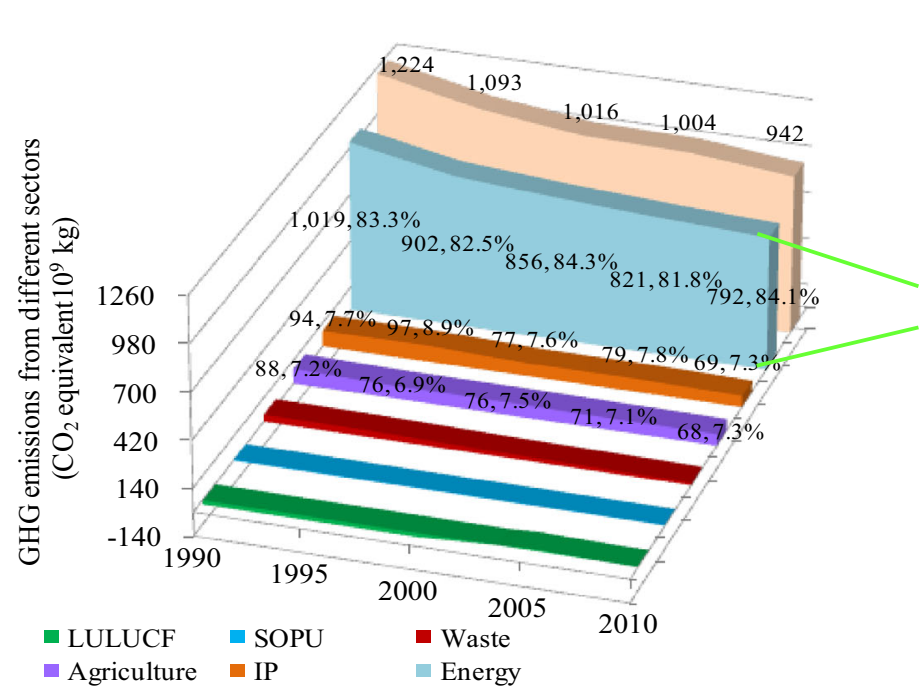

(b)

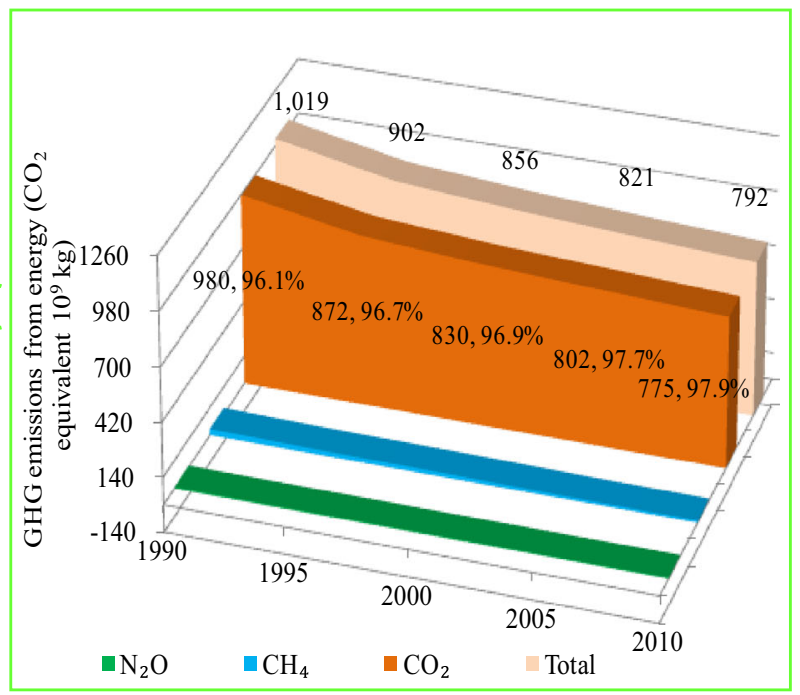

Fig. 11 Dynamic spectrum of GHG emissions in Germany divided by sector (LULUCF land use, land-use change and forestry, SOPU solvents and other product use, $I P$ industrial processes)

because systems with hierarchical structure are proven ordered and low entropy; (3) related measures should be implemented to reduce GHG emissions and decrease the embodied entropy according to the multilayer analysis results where the bigger contributors to GHG emissions need more investment in both management and research; and (4) measures of emissions reduction with less uncertainty (information is symmetric and definite), more controllability (measure is controllable and helpful to make the system in order), and high practicability (effect is beneficial and predictable) are of more priority than that with more uncertainty, less controllability and lower practicability.

The first and second points have been implemented by the spectrum analysis conducted in this paper. The third point still needs more investment and verification where the thermodynamic hypothesis and calculations are necessary. And the last one can be considered in the actual management. For instance, although tax on carbon emissions is regarded as an economically efficient policy for reducing GHG emissions, it is not the first short-term choice since it needs much input of negative entropy from international consensus which is impossible to be decided and controlled by a single country. On the contrary, establishing strict standards for carbon emissions and supporting research on carbon emission reduction are more effective at the current stage due to its controllability and practicability. Of course, more details need to be considered during the actual practice, e.g., economic cost, technological feasibility, and psychological acceptability.

\section{Conclusions}

Abstracting information from the accounting results of GHG emissions is helpful for the public and policy makers, because it can obtain a clear contour of the overall situation of GHG emissions and then facilitate the decision-making process. The concept of spectrum analysis was introduced and defined in this paper to efficiently summarizing and abstracting important information directly from the accounting results in a unified way. Under its guidance, a multilayer analysis framework for GHG emissions represented by a pyramid was established, and thus, the compositional structure of GHG emissions was dissected layer by layer. Finally, the highly generalized structure of GHG emissions was acquired and clearly represented by an ordered spectrum. The spectrum can help confirm the priorities for reducing emissions in the future, which is not only beneficial to government decision making, but also instructive for scientific researchers and technological developers.

The GHG emissions in Germany during 1990-2012 were taken as a case study, which revealed that $\mathrm{CO}_{2}$ accounted for the biggest proportion of the total GHG emissions among all GHG gases, while the energy sector was established as the biggest contributor to the total GHG emissions of all sectors. It is suggested that the government could dictate policies for the reduction in $\mathrm{CO}_{2}$ emissions by establishing strict standards of $\mathrm{CO}_{2}$ emissions, especially for the energy sector, confirming quantitative targets for $\mathrm{CO}_{2}$ emissions reduction, and supporting further scientific 
research and technological development on $\mathrm{CO}_{2}$ emissions reduction with particular focus on the energy sector.

As a baseline, the spectrum analysis of GHG emissions proposed in this paper can be further developed in the future from different aspects. First, it is hopeful to establish a low-entropy management framework for GHG emissions, with the goal of obtaining beneficial outcome (e.g., entropy decrease in GHG emissions and management itself) by effective measures (e.g., those with efficiency and practicability). Second, real-time spectrum analysis of GHG emissions is also helpful to simplify the accounting of GHG emission, which requires the progress in automatic monitoring technology. Moreover, dynamic modeling and mechanism analysis will also be useful to quantitatively show the changes in GHG emissions with the implementation of certain regulations or the alteration of certain variables.

Acknowledgments This work was supported by the Fund for Innovative Research Group of the National Natural Science Foundation of China (Grant No. 51421065), the National Natural Science Foundation of China (No. 41371482), and the National Key Technology R\&D Program (No. 2012BAK30B03).

\section{References}

CDIAC (Carbon Dioxide Information Analysis Center) (2015) Fossilfuel $\mathrm{CO}_{2}$ emissions. Oak Ridge National Laboratory (ORNL). http://cdiac.ornl.gov/trends/emis/meth_reg.html. Accessed on 17 June 2016

Chang TC, Lin SJ (1999) Grey relation analysis of carbon dioxide emissions from industrial production and energy uses in Taiwan. J Environ Manag 56(4):247-257

Chen ZM, Chen GQ (2011) Embodied carbon dioxide emission at supra-national scale: a coalition analysis for G7, BRIC, and the rest of the world. Energy Policy 39(5):2899-2909

Chen GQ, Zhang B (2010) Greenhouse gas emissions in China 2007: inventory and input-output analysis. Energy Policy 38:6180-6193

Choi K-H, Ang BW (2001) A time-series analysis of energy-related carbon emissions in Korea. Energy Policy 29(13):1155-1161

Christen A, Coops NC, Kellett R, Crawford B, Heyman E, Olchovski I, Tooke R, van der Laan M (2010) A LiDARbased urban metabolism approach to neighbourhood scale energy and carbon emissions modelling. University of British Columbia. https://circle.ubc.ca/handle/2429/42442. Accessed on 17 June 2016

de Jong B, Anaya C, Masera O, Olguín M, Paz F, Etchevers J, Martínez RD, Guerrero G, Balbontín C (2010) Greenhouse gas emissions between 1993 and 2002 from land-use change and forestry in Mexico. For Ecol Manag 260:1689-1701

Dhakal S (2004) Urban energy use and greenhouse gas emissions in Asian mega-cities: Polices for sustainable future. http://cleanair initiative.org/portal/node/2385. Accessed on 17 June 2016

Duan J (2012) The study on business growth process management entropy model. Phys Procedia 24:2105-2110

EDGAR (Emission Database for Global Atmospheric Research), Joint Research Center, European Commission (2015) $\mathrm{CO}_{2}$ time series 1990-2014 per region/country. http://edgar.jrc.ec.europa.eu/over view.php?v=CO2ts1990-2014. Accessed on 17 June 2016
EEA (European Environment Agency) (2014) http://www.eea.europa. eu/data-and-maps/data/data-viewers/greenhouse-gases-viewer. Accessed on 17 June 2016

Fan J, Guo XM, Marinova D, Wu YR, Zhao DT (2012) Embedded carbon footprint of Chinese urban households: structure and changes. J Clean Prod 33:50-59

Flessa H, Ruser R, Dörsch P, Kamp T, Jimenez MA, Munch JC, Beese $\mathrm{F}$ (2002) Integrated evaluation of greenhouse gas emissions $\left(\mathrm{CO}_{2}, \mathrm{CH}_{4}, \mathrm{~N}_{2} \mathrm{O}\right)$ from two farming systems in southern Germany. Agric Ecosyst Environ 91:175-189

Garg A, Bhattachary S, Shukla PR, Dadhwal VK (2001) Regional and sectoral assessment of greenhouse gas emissions in India. Atmos Environ 35:2679-2695

Glaeser EL, Kahn ME (2010) The greenness of cities: carbon dioxide emissions and urban development. J Urban Econ 67(3):404-418

Hao Y, Su MR, Zhang LX, Cai YP, Yang ZF (2015) Integrated accounting of urban carbon cycle in Guangyuan, a mountainous city of China: the impacts of earthquake and reconstruction. J Clean Prod 103:231-240

Hossain S (2012) An econometric analysis for $\mathrm{CO}_{2}$ emissions, energy consumption, economic growth, foreign trade and urbanization of Japan. Low Carbon Econ 3:92-105

Houghton RA, Hackler JL (1999) Emissions of carbon from forestry and land-use change in tropical Asia. Glob Change Biol 5(4):481-492

Houghton JT, Meira Filho LG, Bruce JP, Lee H, Callander BA, Haites E, Harris N, Maskell K (1995) Climate change 1994: radiative forcing of climate change and an evaluation of the IPCC IS92 emissions scenarios. Cambridge University Press, Cambridge

IEA (International Energy Agency) (2014) Energy, climate change and environment-2014 insights. http://www.iea.org/Textbase/ npsum/EECC2014sum.pdf. Accessed on 17 June 2016

IPCC (Intergovernmental Panel on Climate Change) (1996) Revised 1996 IPCC guidelines for national greenhouse gas inventories. http://www.ipcc-nggip.iges.or.jp/public/gl/invs1.html. Accessed on 17 June 2016

IPCC (Intergovernmental Panel on Climate Change) (2014) IPCC assessment reports. http://www.ipcc.ch/publications_and_data/ publications_and_data_reports.shtml. Accessed on 17 June 2016

IPCC (Intergovernmental Panel on Climate Change) (2016) Frequently asked questions. http://www.ipcc-nggip.iges.or.jp/faq/ faq.html. Accessed on 17 June 2016

Liu LC, Wu G, Wang JN, Wei YM (2011) China's carbon emissions from urban and rural households during 1992-2007. J Clean Prod 19(15):1754-1762

Liu Z, Guan DB, Wei W, Davis SJ, Ciais P, Bai J, Peng SS, Zhang Q, Hubacek K, Marland G, Andres RJ, Crawford-Brown D, Lin JT, Zhao HY, Hong CP, Boden TA, Feng KS, Peters GP, Xi FM, Liu JG, Li Y, Zhao Y, Zeng N, He KB (2015) Reduced carbon emission estimates from fossil fuel combustion and cement production in China. Nature 524:335-338

Lu WW, Chen C, Su MR, Chen B, Cai YP, Xing T (2013) Urban energy consumption and related carbon emission estimation: a study at the sector scale. Front Earth Sci 7(4):480-486

Ma K (2005) Study on enterprise's organizational reengineering based on the theories of management entropy and dissipative structure. Dissertation for the Master Degree of Management, Harbin University of Science and Technology, Harbin (in Chinese)

Matsuo Y, Suzuki K, Nagatomi Y, Suehiro S, Komiyama R (2012) Estimating global $\mathrm{CO}_{2}$ emission constraints and energy supply/ demand structure in 2050 with MARKAL model. IEEJ 1-16. http://eneken.ieej.or.jp/data/4630.pdf. Accessed on 17 June 2016

Molt S, Schumann P, Laege E, Fahl U, Voss A (1996) Integrated strategies to reduce greenhouse gas emissions in Germany. Energy Convers Manag 37(6-8):735-740 
National Aeronautics and Space Administration (NASA) (2010) NASA Carbon Monitoring System Scoping Study Workshop Report. http://cce.nasa.gov/cce/cms/2010\%20CMS_Scoping\% 20Study\%20Workshop\%20Report.pdf. Accessed on 17 June 2016

Olonscheck M, Holsten A, Kropp JP (2011) Heating and cooling energy demand and related emissions of the German residential building stock under climate change. Energy Policy 39:4795-4806

Perch-Nielsen S, Sesartic A, Stucki M (2010) The greenhouse gas intensity of the tourism sector: the case of Switzerland. Environ Sci Policy 13(2):131-140

Powell A (2015) The Rainmaker in the Amazon, gauging the resilience of a rainforest. http://issuu.com/huce/docs/fallnewslet ter-final-high. Accessed on 17 June 2016

Ren SG, Yin HY, Chen XH (2014) Using LMDI to analyze the decoupling of carbon dioxide emissions by China's manufacturing industry. Environ Dev 9:61-75

Salt JE, Moran A (1997) International greenhouse gas inventory systems: a comparison between CORINAIR and IPCC methodologies in the EU. Glob Environ Change 7(4):317-336

Schumacher K, Sands RD (2006) Innovative energy technologies and climate policy in Germany. Energy Policy 34:3929-3941

Shao L, Chen GQ, Chen ZM, Guo S, Han MY, Zhang B, Hayat T, Alsaedi A, Ahmad B (2014) Systems accounting for energy consumption and carbon emission by building. Commun Nonlinear Sci Numer Simul 19(6):1859-1873

Stern N (2006) Stern review: the economics of climate change. http:// webarchive.nationalarchives.gov.uk/+/http://www.hm-treasury. gov.uk/sternreview_index.htm. Accessed on 17 June 2016
Streets DG, Jiang KJ, Hu XL, Sinton JE, Zhang XQ, Xu DY, Jacobson MZ, Hansen JE (2001) Recent reductions in China's greenhouse gas emissions. Science 294(30):1835-1837

Su MR, Liang C, Chen B, Chen SQ, Yang ZF (2012) Low-carbon development patterns: observations of typical Chinese cities. Energies 5(2):291-304

UNFCCC (United Nations Framework Convention on Climate Change) (2014) http://unfccc.int/national_reports/annex_i_ghg_ inventories/national_inventories_submissions/items/8108.php. Accessed on 17 June 2016

WRI (World Resources Institute) (2014) Interactive: Carbon emissions past, present and future. http://www.wri.org/resources/ data-visualizations/carbon-emissions-past-present-and-future-int eractive. Accessed on 17 June 2016

$\mathrm{Xu}$ FJ (2010) Research on the coordinated and control ability of network organization based on management entropy. Dissertation for the Master Degree of Management, Harbin Engineering University, Harbin (in Chinese)

You F, Hu D, Zhang HT, Guo Z, Zhao YH, Wang BN, Yuan Y (2011) Carbon emissions in the life cycle of urban building system in China-a case study of residential buildings. Ecol Complex 8(2):201-212

Zhang L, Lei J, Zhou X, Zhang XL, Dong W, Yang Y (2014) Changes in carbon dioxide emissions and LMDI-based impact factor decomposition: the Xinjiang Uygur autonomous region as a case. J Arid Land 6(2):145-155

Zhao RQ, Huang XJ, Zhong TY, Liu Y, Chuai XW (2014) Carbon flow of urban system and its policy implications: the case of Nanjing. Renew Sustain Energy Rev 33:589-601 